\title{
Analysis of the Effect of Proton Pump Inhibitors on the Course of Common COVID-19
}

xiaoyu ZHANG ( $\nabla$ zhangxiaoyuprc@163.com )

Shanghai Public Health Clinical Center

\section{Haibing Wu}

Shanghai Public Health Clinical Center

\section{Yun Ling}

Shanghai Public Health Clinical Center

\section{Liang Chen}

Shanghai Public Health Clinical Center

\section{Research Article}

Keywords: COVID-19, SARS-CoV-2, Proton pump inhibitors, SARS-CoV-2 clearance, Hospitalization days

Posted Date: October 15th, 2020

DOl: https://doi.org/10.21203/rs.3.rs-90738/v1

License: (9) This work is licensed under a Creative Commons Attribution 4.0 International License. Read Full License 


\section{Abstract}

Background/aims: This study is to evaluate the effect of proton pump inhibitors on the course of common COVID-19.

Methods: Clinical data of common COVID-19 patients admitted to the Shanghai Public Health Clinical Center for treatment from January 20, 2020 to March 16, 2020 were collected. A retrospective study was conducted and the patients were divided into two groups according to whether they used proton pump inhibitors or not. The differences in SARS-CoV-2 clearance and hospital stay between the two groups were compared by univariate and multivariate analyses.

Results: A total of 154 COVID-19 common cases were included in this study, including 80 males (51.9\%), 35 patients $(22.7 \%)$ in the proton pump inhibitors group, and 119 patients $(77.3 \%)$ in the control group. In the proton pump inhibitors group and the control group, the duration of the SARS-CoV-2 clearance were 7(6-9) and 7(6-11) days, and the duration of the hospital stay was 21(16-25) and 20(15-26) days, respectively. There was no significant difference between the two groups in the cumulative incidence of the SARS-CoV-2 clearance and the discharge, all P $>0.05$. Multivariate analysis showed that chronic gastropathy prolonged the duration of SARS-CoV-2 clearance, the HR was 20.924(3.547-123.447). Hypertension, chronic obstructive pulmonary disease, chronic liver disease and malignant tumor all increased the duration of hospital stay for COVID-19, and the HR were 1.820 (1.073-3.085), 4.370 (1.20515.844), 9.011 (2.681-30.290) and 5.270 (1.237-22.456), respectively; the duration of the hospital stay in COVID-19 patients was shortened by the SARS-CoV-2 clearance, and the HR was 0.907 (0.869-0.947); all $P<0.05$.

Conclusion: Proton pump inhibitors use has no effect on the prolonging or shortening of the course of adults hospitalized with COVID-19.

\section{Introduction}

The disease burdens of coronavirus disease 2019 (COVID-19), caused by severe acute respiratory syndrome coronavirus-2 (SARS-CoV-2), have been continuously increasing. ${ }^{[1]}$ As of 6:50 p.m. Edt on 22 May 2020, 4,995,996 confirmed cases of COVID-19, including 327,821 deaths, have been reported to WHO. ${ }^{[2]}$ Some COVID-19 patients have obvious gastrointestinal symptoms ${ }^{[3-4]}$, and some basic diseases and therapeutic drugs may cause damage to the gastric mucosa; which can lead to PPIs being used to varying degrees in the treatment of COVID-19.

However, proton pump inhibitors (PPIs) have been found in several clinical studies to increase the incidence of community-acquired pneumonia or hospital-acquired pneumonia. ${ }^{[5-12]}$ On the other hand, studies have showed that PPIs did not increase the incidence of pneumonia. They believed that the increased incidence of pneumonia caused by PPIs was due to confounding factors, and PPIs itself was 
not an independents factor affecting the occurrence of pneumonia. ${ }^{[13-16]}$ In addition, studies have shown that PPIs can effectively inhibit virus and can be tried to treat viral infection and respiratory disease. ${ }^{[17-18]}$

It is not clear whether PPIs will have a significant impact on COVID-19. The purpose of this study was to analyze whether PPIs has relation with the SARS-CoV-2 clearance and the length of the hospital stay in COVID-19.

\section{Methods}

\section{Study design}

A retrospective cohort study design was conducted in the Shanghai Public Health Clinical Center affiliated to Fudan University, a designated tertiary teaching hospital for the treatment of SARS-CoV-2 infection. Patients with common COVID-19 confirmed diagnosis during the first three days in the hospital from January 20, 2020 to March 16, 2020 were included, and those cases would be followed up to discharge. The informed consent of patient was collected, including their data being used for research, and that this study was conducted in accordance with the Declaration of Helsinki.

\section{Patients and definitions}

A total of 298 adults admitted were diagnosed with common COVID-19 in the first three days after admission.

common COVID-19 met the following criteria: (1) the patients have epidemiological contact history or clinical manifestations; (2) pneumonia can be seen on imaging; (3) the SARS-CoV-2 nucleic acid test was positive by real-time fluorescence RT-PCR; (4) respiratory rate $>12$ times $/ \mathrm{min}$ and $<30$ times $/ \mathrm{min}$, oxygenation index $>300 \mathrm{mmHg}$, oxygen concentration $>93 \%$ in resting state; (5) no shock and organ failure.

SARS-CoV-2 clearance met the following criteria: the SARS-CoV-2 nucleic acid test was negative for two consecutive pharyngeal swabs, sampling time interval at least 24 hours.

Discharge met the following criteria: (1) body temperature returned to normal for more than 3 days; (2) respiratory symptoms improved significantly; (3) pulmonary CT scan showed basic absorption of acute exudative lesions; (4) the patients obtained SARS-CoV-2 clearance.

\section{Inclusion and exclusion criteria}

A total of 154 cases were enrolled in the analysis. Of the 144 cases excluded, 27 cases were given PPIs for less than 3 days before the SARS-CoV- 2 clearance, 12 cases had no nucleic acid test within the first three days after admission, 104 cases lacked continuous detection data required for the study design, and 1 case died who was not exposed to PPIs. See Fig. 1 for details. 
Case inclusion criteria: (1) cases were diagnosed with common COVID-19 within first three days after admission; (2) cases were man and non-pregnant women; (3) age > 18 years old; (4) the SARS-CoV-2 nucleic acid were tested positive for the cases during the first three days after hospitalization; (5) the nucleic acid test of SARS-CoV-2 was continuous; (6) cases in the PPIs group were treated with PPIs for more than 3 days before the SARS-CoV-2 clearance, while cases in the control group had not received drugs to suppress gastric acid secretion; (7) the daily dose of omeprazole was $20 \mathrm{mg}$ or $40 \mathrm{mg}$, or the daily dose of rabeprazole was $20 \mathrm{mg}$.

Case exclusion criteria: (1) the cases used drugs to inhibit the secretion of gastric acid within 30 days before admission; (2) the cases in which the interval of continuous sample for SARS-COV-2 nucleic acid testing was more than 48 hours; (3) cases in the PPIs group were treated with PPIs for less than 3 days before the SARS-CoV-2 clearance; (4) the cases with incomplete research data; (5) the cases died in the course of hospitalization.

\section{Case grouping and requirements}

PPIs group: the cases were exposed to PPIs and met the above inclusion and exclusion criteria. A total of 35 eligible cases were included in the PPIs group.

Control group: the cases were not exposed to drugs that suppressed the secretion of gastric acid and met the above inclusion and exclusion criteria. A total of 119 eligible cases were included in the control group.

\section{Data sources and indicators}

The demographic and clinical data was collected from electronic medical record (EMR) including hospital information system (HIS), laboratory information system (LIS) and radiology information system (RIS) of the Shanghai Public Health Clinical Center. The demographic and clinical data included age and sex of the patients, the number of pulmonary lobe inflammation by COVID-19 on the CT scan, the onset times, the duration of the SARS-CoV-2 clearance after hospitalization and the duration of hospital stay; history of hypertension(HPT), diabetes mellitus(DM), cardiovascular disease(CVD), chronic obstructive pulmonary disease(COPD), chronic liver disease(CLD), chronic gastric disease(CGD), chronic kidney disease(CDK), malignant tumor(MT), alanine aminotransferase (ALT), aspartate aminotransferase (AST), creatine kinase (CK), lactate dehydrogenase (LDH), albumin (ALB), prealbumin (PA), creatinine (Cr), Ddimer (D-D), leukocyte (WBC), neutrophils (Neu), lymphocyte(Lym), blood platelet (PLT), and CD4-positive T-lymphocytes (CD4, CD4 cells). All the baseline information was collected in the 24 hours after admission.

The nucleic acid test specimens of the SARS-CoV-2 in this study were nasopharyngeal swabs, which were tested by the Shanghai Municipal Center for Disease Control and Prevention before admission, while sampled and tested in the Shanghai Public Health Clinical Center after admission. All the cases which were admitted to the Shanghai Public Health Clinical Center were tested positive for SARS-CoV-2 nucleic acid in the Shanghai Municipal Center for Disease Control and Prevention before hospitalization.

\section{Statistical analyses}


The date was described as median (quartile spacing) or numbers (\%). Person chi-square test and fisher exact probability method were used for the counting data. The normality of continuous variables was tested by K-S test. T test was used for the differences between data groups conforming to normal distribution, while Manny-Whitney $\mathrm{U}$ test was used for the differences between data groups not conforming to normal distribution.

The cumulative probability of the SARS-CoV-2 clearance or the discharge was conducted through KaplanMeier statistics, and the difference was examined by Log-rank test. The possible risk factors of the SARSCoV-2 clearance or the discharge were investigated with Cox proportional hazards $(\mathrm{PH})$ regression models for univariate and multivariate analyses to estimate hazard ratios (HRs) and $95 \%$ confidence intervals (Cls). PH assumption was verified using Schoenfeld residuals.

SPSS software version 23.0 (SPSS Inc. Chicago, IL, USA,) was used for statistical analysis of the data. The $P$ value of two-sided less than 0.05 was considered as statistically significant.

\section{Results}

\section{Baseline status of COVID-19 cases}

A total of 154 COVID-19 cases were included in this study, including 80 males (51.9\%), 35 cases (22.7\%) in the PPIs group, and 119 cases $(77.3 \%)$ in the control group. There was no significant difference between the PPIs group and the control group in age, sex, hypertension, diabetes mellitus, cardiovascular disease, chronic obstructive pulmonary disease, chronic liver disease, chronic gastric disease, chronic kidney disease, malignant tumor, the number of pulmonary lobe inflammation on the CT scan, the onset times, duration of the SARS-CoV-2 clearance, hospital stays, alanine aminotransferase, aspartate aminotransferase, creatine kinase, lactate dehydrogenase, albumin, prealbumin, creatinine, D-dimer, leukocyte, neutrophils, lymphocytes, platelet and CD 4 cells; all $P>0.05$. See Table 1 for details. 
Table 1

Baseline data among the enrolled cases of COVID-19

\begin{tabular}{|c|c|c|c|}
\hline & PPIs group $(n=35)$ & Control group $(n=119)$ & $\mathbf{P}$ \\
\hline Age & $50(35-65)$ & $52(36-64)$ & 0.947 \\
\hline Sex,male(\%) & $18(51.4)$ & $62(52.1)$ & 0.944 \\
\hline HPT(\%) & $7(20)$ & $28(23.5)$ & 0.661 \\
\hline $\mathrm{DM}(\%)$ & $2(5.7)$ & $10(8.4)$ & 0.870 \\
\hline CVR(\%) & $2(5.7)$ & $5(4.2)$ & 1.000 \\
\hline $\operatorname{COPD}(\%)$ & $1(2.9)$ & $2(1.7)$ & 0.541 \\
\hline $\operatorname{CLD}(\%)$ & $1(2.9)$ & $3(2.5)$ & 1.000 \\
\hline $\operatorname{CGD}(\%)$ & $0(0)$ & $2(1.7)$ & 1.000 \\
\hline CKD $(\%)$ & $2(5.7)$ & $0(0)$ & 0.051 \\
\hline MT(\%) & $0(0)$ & $3(2.5)$ & 1.000 \\
\hline NPLI & $3(2-5)$ & $4(2-5)$ & 0.660 \\
\hline The onset times(days) & $3(2-6)$ & $4(2-7)$ & 0.418 \\
\hline SARS-CoV-2 clearance(days) & $7(6-9)$ & $7(6-11)$ & 0.691 \\
\hline Hospital stays(days) & $21(16-25)$ & $20(15-26)$ & 0.507 \\
\hline $\operatorname{ALT}(U / L)$ & $21(15-30)$ & $22(16-35)$ & 0.643 \\
\hline AST (U/L) & $26(20-42)$ & $25(20-33)$ & 0.533 \\
\hline CK (U/L) & $102(55-194)$ & $80(55-127)$ & 0.190 \\
\hline LDH (U/L) & $231(193-305)$ & 219(190-293) & 0.745 \\
\hline ALB $(g / L)$ & $41.0(37.9-44.0)$ & $41.2(38.1-44.1)$ & 0.528 \\
\hline PA (mg/L) & $151(93-193)$ & $158(104-207)$ & 0.355 \\
\hline $\mathrm{Cr}$ (umol/L) & $70.5(52.4-77.3)$ & $61.3(50.5-77.1)$ & 0.328 \\
\hline D-D (mg/L) & $0.36(0.28-0.50)$ & $0.37(0.26-0.64)$ & 0.828 \\
\hline WBC $\left(10^{\wedge} 9 / L\right)$ & $4.4(3.7-5.7)$ & $4.9(4.0-5.9)$ & 0.227 \\
\hline $\mathrm{Neu}(\%)$ & $65.4(55.2-70.6)$ & $66.6(58.2-72.6)$ & 0.255 \\
\hline Lym ( 10^9/L) & $1.04(0.73-1.38)$ & $1.13(0.79-1.52)$ & 0.196 \\
\hline PLT (10^9/L) & $163(121-201)$ & $176(143-218)$ & 0.218 \\
\hline
\end{tabular}




\begin{tabular}{|c|c|c|c|}
\hline & PPIs group $(n=35)$ & Control group $(n=119)$ & $\mathbf{P}$ \\
\hline CD4 (cell/ul) & $411(264-717)$ & $456(302-650)$ & 0.711 \\
\hline \multicolumn{4}{|c|}{$\begin{array}{l}\text { PPIs: proton pump inhibitors; HPT: hypertension; DM-diabetes mellitus; CVD: cardiovascular disease; } \\
\text { COPD: chronic obstructive pulmonary disease; CLD: chronic liver disease; CGD: chronic gastric } \\
\text { disease; CKD: chronic kidney disease; MT: malignant tumor; NPLI: number of pulmonary lobe } \\
\text { inflammation; ALT: anine aminotransferase, AST: aspartate aminotransferase, CK: creatine kinase, } \\
\text { LDH: lactate dehydrogenase, ALB: albumin, PA: prealbumin, Cr: creatinine, D-D: D-dimer, WBC: } \\
\text { leukocyte, Neu: neutrophils, Lym: lymphocyte, PLT: blood platelet, CD4: CD } 4 \text { cells, CD4-positive T- } \\
\text { lymphocytes. }\end{array}$} \\
\hline
\end{tabular}

\section{Comparison of virus clearance and hospital stay}

The duration of the SARS-CoV-2 clearance in the PPIs group and the control group was 7(6-9) and 7(6$11)$ days, respectively. There was no significant difference in the cumulative incidence of the SARS-CoV-2 clearance between the two groups, $P=0.123$. The duration of hospital stay for COVID-19 cases was 21(16-25) days in the PPIs group and 20(15-26) days in the control group. There was no significant difference between the two groups in the cumulative incidence of the discharge for COVID-19 cases, $P=$ 0.812. See Table 1 and Fig. 2 for details

\section{Analysis of the factors influencing viral clearance and hospital stay}

\section{Analysis of factors affecting the SARS-CoV-2 clearance of COVID-19}

Univariate analysis showed that chronic gastropathy prolonged the duration of the SARS-CoV-2 clearance in COVID-19 cases, HR 15.202(3.331-69.377), $\mathrm{P}<0.001$. Multivariate analysis showed that chronic gastropathy prolonged the duration of SARS-CoV-2 clearance in COVID-19 cases, HR was 20.924(3.547123.447), $P<0.001$. There was no significant difference in the remainder, and all $P>0.05$. See Table 2 for details. 
Table 2

Univariate and Multivariate analyses of predictive factors for SARS-CoV-2 clearance in COVID-19 patients

\begin{tabular}{|c|c|c|c|c|}
\hline \multirow[t]{2}{*}{ Variable } & \multicolumn{2}{|l|}{ Univariate analysis } & \multicolumn{2}{|l|}{ Mutivariate analysis } \\
\hline & HR & $\mathbf{P}$ & HR & $\mathbf{P}$ \\
\hline Age: $\geq 60 /<60$ (years) & $0.837(0.599-1.169)$ & 0.297 & $0.984(0.645-1.502)$ & 0.941 \\
\hline Sex: male/female & $0.946(0.686-1.304)$ & 0.734 & $0.824(0.566-1.200)$ & 0.313 \\
\hline PPIs/not-PPIs & $1.309(0.893-1.918)$ & 0.168 & $1.575(0.993-2.499)$ & 0.054 \\
\hline HPT/not-HPT & $1.187(0.813-1.733)$ & 0.374 & $1.576(0.959-2.589)$ & 0.073 \\
\hline DM/not-DM & $0.909(0.503-1.642)$ & 0.751 & $1.136(0.513-2.517)$ & 0.754 \\
\hline CVD/not-CVD & $0.596(0.292-1.218)$ & 0.156 & $0.414(0.161-1.065)$ & 0.067 \\
\hline COPD/not-COPD & $1.397(0.443-4.403)$ & 0.568 & $1.344(0.385-4.696)$ & 0.643 \\
\hline CLD/not-CLD & $2.037(0.750-5.532)$ & 0.163 & $2.293(0.642-8.193)$ & 0.201 \\
\hline CGD/not-CGD & $15.202(3.331-69.377)$ & $\llbracket 0.001$ & 20.924(3.547-123.447) & $\varangle 0.001$ \\
\hline CKD/not-CKD & $0.944(0.233-3.821)$ & 0.935 & $1.105(0.151-8.087)$ & 0.922 \\
\hline MT/not-MT & $1.144(0.364-3.599)$ & 0.818 & $0.666(0.155-2.859)$ & 0.584 \\
\hline NPLI & $1.012(0.913-1.121)$ & 0.821 & $0.999(0.870-1.146)$ & 0.985 \\
\hline The onset times(days) & $0.993(0.952-1.035)$ & 0.735 & $0.993(0.948-1.040)$ & 0.764 \\
\hline CK: $\geq 198 /<198(U / L)$ & $1.028(0.658-1.606)$ & 0.904 & $0.908(0.527-1.567)$ & 0.730 \\
\hline $\mathrm{LDH}: \geq 252 /<152(\mathrm{U} / \mathrm{L})$ & $1.090(0.785-1.514)$ & 0.607 & $1.026(0.643-1.635)$ & 0.916 \\
\hline ALB: $<35 / \geq 35(\mathrm{~g} / \mathrm{L})$ & $1.259(0.662-2.395)$ & 0.483 & $0.985(0.408-2.377)$ & 0.973 \\
\hline $\mathrm{PA}:<280 / \geq 280(\mathrm{mg} / \mathrm{L})$ & $2.075(0.512-8.410)$ & 0.307 & $2.812(0.427-18.515)$ & 0.282 \\
\hline Cr: $\geq 104 /<104$ (umol/L) & $0.933(0.345-2.527)$ & 0.892 & $0.929(0.270-3.200)$ & 0.907 \\
\hline $\mathrm{D}-\mathrm{D}: \geq 0.5 /<0.5(\mathrm{mg} / \mathrm{L})$ & $1.053(0.743-1.493)$ & 0.771 & $1.006(0.601-1.685)$ & 0.981 \\
\hline \multicolumn{5}{|l|}{ WBC } \\
\hline WBC: $<4 / 4-10\left(10^{\wedge} 9 / \mathrm{L}\right)$ & $1.425(0.45-4.517)$ & 0.547 & $1.414(0.332-6.015)$ & 0.639 \\
\hline WBC > 10/4-10 (10^9/L) & $1.251(0.385-4.063)$ & 0.710 & $1.322(0.31-5.643)$ & 0.706 \\
\hline Neu:>70/ $>70(\%)$ & $1.067(0.754-1.510)$ & 0.713 & $1.236(0.778-1.964)$ & 0.370 \\
\hline LYM $<1.1 / \geq 1.1\left(10^{\wedge} 9 / \mathrm{L}\right)$ & $0.911(0.66-1.257)$ & 0.570 & $0.910(0.589-1.408)$ & 0.673 \\
\hline \multicolumn{5}{|l|}{ PLT } \\
\hline PLT:囚100/100-300 (10^9/L) & $0.713(0.176-2.892)$ & 0.636 & $1.502(0.277-8.152)$ & 0.638 \\
\hline
\end{tabular}




\begin{tabular}{|c|c|c|c|c|}
\hline \multirow[t]{2}{*}{ Variable } & \multicolumn{2}{|l|}{ Univariate analysis } & \multicolumn{2}{|l|}{ Mutivariate analysis } \\
\hline & HR & $\mathbf{P}$ & HR & $\mathbf{P}$ \\
\hline PLT:>300/100-300 (10^9/L) & $0.817(0.164-4.069)$ & 0.805 & $1.662(0.217-12.737)$ & 0.625 \\
\hline CD4 < 500/ $\geq 500(\mathrm{cell} / \mathrm{ul})$ & $0.955(0.689-1.325)$ & 0.784 & $0.796(0.509-1.246)$ & 0.319 \\
\hline $\mathrm{ALT}>60 / \leq 60(\mathrm{U} / \mathrm{L})$ & $1.709(0.919-3.177)$ & 0.090 & $1.739(0.865-3.493)$ & 0.120 \\
\hline AST > 60/ $\leq 60(\mathrm{U} / \mathrm{L})$ & $1.717(0.834-3.533)$ & 0.142 & $1.387(0.466-4.128)$ & 0.557 \\
\hline \multicolumn{5}{|c|}{$\begin{array}{l}\text { PPIs: proton pump inhibitors; HPT: hypertension; DM-diabetes mellitus; CVD: cardiovascular disease; } \\
\text { COPD: chronic obstructive pulmonary disease; CLD: chronic liver disease; CGD: chronic gastric } \\
\text { disease; CKD: chronic kidney disease; MT: malignant tumor; NPLI: number of pulmonary lobe } \\
\text { inflammation; ALT: anine aminotransferase, AST: aspartate aminotransferase, CK: creatine kinase, } \\
\text { LDH: lactate dehydrogenase, ALB: albumin, PA: prealbumin, Cr: creatinine, D-D: D-dimer, WBC: } \\
\text { leukocyte, Neu: neutrophils, Lym: lymphocyte, PLT: blood platelet, CD4: CD 4 cells, CD4-positive T- } \\
\text { lymphocytes. }\end{array}$} \\
\hline
\end{tabular}


Table 3

Univariate and Multivariate analyses of predictive factors for discharge in COVID-19 patients

\begin{tabular}{|c|c|c|c|c|}
\hline \multirow[t]{2}{*}{ Variable } & \multicolumn{2}{|l|}{ Univariate analysis } & \multicolumn{2}{|l|}{ Mutivariate analysis } \\
\hline & HR & $\mathbf{P}$ & HR & $\mathbf{P}$ \\
\hline Age: $\geq 60 /<60$ (years) & $0.759(0.543-1.063)$ & 0.108 & $0.652(0.410-1.039)$ & 0.072 \\
\hline Sex:male/female & $0.894(0.651-1.230)$ & 0.492 & $0.962(0.655-1.414)$ & 0.845 \\
\hline PPIs/not-PPIs & $1.044(0.714-1.528)$ & 0.823 & $1.064(0.651-1.740)$ & 0.805 \\
\hline HPT/not-HPT & $1.250(0.854-1.829)$ & 0.250 & $1.820(1.073-3.085)$ & 0.026 \\
\hline DM/not-DM & $1.051(0.581-1.899)$ & 0.870 & $0.595(0.255-1.389)$ & 0.230 \\
\hline CVD/not-CVD & $0.917(0.429-1.962)$ & 0.823 & $1.304(0.481-3.538)$ & 0.602 \\
\hline COPD/not-COPD & 2.993(0.946-9.474) & 0.062 & $4.370(1.205-15.844)$ & 0.025 \\
\hline CLD/not-CLD & $6.183(2.18-17.534)$ & 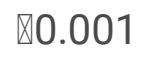 & $9.011(2.681-30.290)$ & $\varangle 0.001$ \\
\hline CGD/not-CGD & $4.155(1.011-17.078)$ & 0.048 & $1.855(0.370-9.292)$ & 0.452 \\
\hline CKD/not-CKD & $1.404(0.346-5.699)$ & 0.635 & $1.911(0.344-10.621)$ & 0.459 \\
\hline MT/not-MT & $2.051(0.65-6.470)$ & 0.220 & $5.270(1.237-22.456)$ & 0.025 \\
\hline NPLI & 0.995(0.897-1.104) & 0.928 & $1.027(0.886-1.191)$ & 0.724 \\
\hline The onset times (days) & $1(0.961-1.041)$ & 0.993 & $1.017(0.972-1.064)$ & 0.463 \\
\hline SARS-CoV-2 clearance (days) & $0.911(0.876-0.948)$ & $\bigotimes 0.001$ & $0.907(0.869-0.947)$ & $\nabla 0.001$ \\
\hline CK: $\geq 198 /<198$ (U/L) & $0.9(0.576-1.405)$ & 0.642 & $0.949(0.537-1.678)$ & 0.858 \\
\hline LDH: $\geq 252 /<152(\mathrm{U} / \mathrm{L})$ & $1.019(0.734-1.415)$ & 0.909 & $0.967(0.597-1.566)$ & 0.892 \\
\hline ALB: $<35 / \geq 35(\mathrm{~g} / \mathrm{L})$ & $0.979(0.514-1.865)$ & 0.949 & $0.630(0.29-1.369)$ & 0.243 \\
\hline 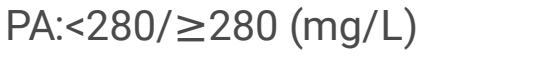 & $1.596(0.395-6.454)$ & 0.512 & $1.200(0.244-5.900)$ & 0.822 \\
\hline Cr: $\geq 104 /<104$ (umol/L) & $1.017(0.376-2.753)$ & 0.974 & $0.885(0.276-2.836)$ & 0.837 \\
\hline $\mathrm{D}-\mathrm{D}: \geq 0.5 /<0.5(\mathrm{mg} / \mathrm{L})$ & 1.101(0.778-1.558) & 0.586 & $1.232(0.755-2.010)$ & 0.404 \\
\hline \multicolumn{5}{|l|}{ WBC } \\
\hline WBC: $<4 / 4-10\left(10^{\wedge} 9 / L\right)$ & $1.071(0.339-3.381)$ & 0.907 & $0.574(0.163-2.021)$ & 0.387 \\
\hline WBC > 10/4-10 (10^9/L) & $0.869(0.267-2.824)$ & 0.815 & $0.540(0.152-1.917)$ & 0.341 \\
\hline 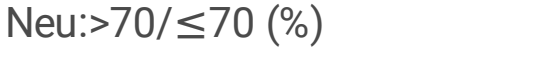 & $1.091(0.773-1.540)$ & 0.620 & 1.392(0.872-2.223) & 0.166 \\
\hline LYM < 1.1/ $\geq 1.1\left(10^{\wedge} 9 / \mathrm{L}\right)$ & $0.822(0.596-1.134)$ & 0.233 & $0.751(0.480-1.173)$ & 0.208 \\
\hline PLT & & & & \\
\hline
\end{tabular}




\begin{tabular}{|lllll|}
\hline $\mathrm{PLT}: \triangle 100 / 100-300\left(10^{\wedge} 9 / \mathrm{L}\right)$ & $1.138(0.28-4.619)$ & 0.856 & $0.927(0.162-5.297)$ & 0.932 \\
\hline $\mathrm{PLT}:>300 / 100-300\left(10^{\wedge} 9 / \mathrm{L}\right)$ & $1.228(0.246-6.117)$ & 0.802 & $0.866(0.123-6.097)$ & 0.886 \\
\hline $\mathrm{CD} 4<500 / \geq 500(\mathrm{cell} / \mathrm{ul})$ & $0.885(0.640-1.224)$ & 0.459 & $1.055(0.659-1.688)$ & 0.824 \\
\hline $\mathrm{ALT}>60 / \leq 60(\mathrm{U} / \mathrm{L})$ & $1.511(0.811-2.815)$ & 0.193 & $1.311(0.643-2.674)$ & 0.456 \\
\hline AST $>60 / \leq 60(\mathrm{U} / \mathrm{L})$ & $1.001(0.490-2.045)$ & 0.998 & $0.760(0.267-2.158)$ & 0.606 \\
\hline
\end{tabular}

PPIs: proton pump inhibitors; HPT: hypertension; DM-diabetes mellitus; CVD: cardiovascular disease; COPD: chronic obstructive pulmonary disease; CLD: chronic liver disease; CGD: chronic gastric disease; CKD: chronic kidney disease; MT: malignant tumor; NPLI: number of pulmonary lobe inflammation; ALT: anine aminotransferase, AST: aspartate aminotransferase, CK: creatine kinase, LDH: lactate dehydrogenase, ALB: albumin, PA: prealbumin, Cr: creatinine, D-D: D-dimer, WBC: leukocyte, Neu: neutrophils, Lym: lymphocyte, PLT: blood platelet, CD4: CD4 cells, CD4-positive Tlymphocytes.

\section{Analysis of factors affecting the duration of hospital stay for COVID-19}

Univariate analysis: chronic liver disease and chronic gastric disease prolonged the duration of hospital stay in COVID-19 cases, HR were 6.183(2.18-17.534) and 4.155(1.011-17.078), respectively, all $P<0.05$. The SARS-CoV-2 clearance shortened the duration of hospital stay in COVID-19 cases, HR was 0.911(0.876-0.948), all $P<0.05$. Multivariate analysis: hypertension, chronic obstructive pulmonary disease, chronic liver disease, and malignant tumor prolonged the duration of hospital stay in COVID-19 cases, HR were 1.820 (1.073-3.085), 4.370 (1.205-15.844), 9.011 (2.681-30.290), 5.27 (1.237-22.456), all $\mathrm{P}<0.05$, respectively. The SARS-CoV-2 clearance shortened the duration of hospital stay in COVID-19 cases, HR was 0.907 (0.869-0.947), all $P<0.05$. There was no significant difference in the remainder, and all $P>0.05$. See Table 2 for details.

\section{Discussion}

Patients with gastric acid-related diseases often need to take PPIs for treatment. However, the risk of using PPIs on the occurrence of pneumonia have been reported inconsistently, and the effect of PPIs on the course of COVID-19 has not been reported. Especially in this COVID-19 outbreak, it is difficult to draw on appropriate references regarding the safety or risk of PPIs in COVID-19 cases. Currently, most of the existing studies on the safety or risk of PPIs use are retrospective cohort studies or case-control studies, all of which lacked information on the pathogen of pneumonia. The mechanism of the safety or risk of PPIs has not been fully clarified, and more high-quality design studies are needed to confirm it. This study can not only determine the effect of PPIs on the course of COVID-19, but also further provide the basis to verify whether the PPIs use increases the incidence of pneumonia.

To date, no effective drug treatment for COVID-19 has been found in large sample of high-quality clinical studies $^{[19]}$, except for remdesivir superior to placebo in shortening recovery times in adult patients 
hospitalized with COVID-19 and with evidence of lower respiratory tract infection ${ }^{[20]}$. Therefore, other drugs were not included in the statistical analysis.

In terms of statistical methods, univariate analysis and multivariate analysis were use in this study; because univariate analysis showed that PPIs did not prolong or shorten the duration of SARS-CoV-2 clearance and hospital stay, all indicators were included in the multivariate analysis for progressive analysis, and the results also showed that PPIs did not extend or shorten the duration of SARS-CoV-2 clearance and hospital stay. We also applied the Kaplan-Meier and log-Rank tests, which showed PPIs did not increase or decrease the rate of the SARS-CoV-2 clearance and the discharge.

\section{Key findings}

In this study, we found that PPIs use in common COVID-19 did not prolong or shorten the duration of SARS-CoV-2 clearance or hospital stay. After preliminary screening, chronic gastropathy prolonged the duration of SARS-CoV-2 clearance, while hypertension, chronic bronchitis, chronic liver disease, and malignant tumors prolonged the duration of hospital stay in COVID-19 patients, the SARS-CoV-2 clearance shortened the duration of hospital stay in COVID-19 patients. Primary diseases and comorbidity were the main factors affecting the course of COVID-19, and the etiological treatment was important in COVID-19.

\section{Comparison with related literature}

So far, there have been no reported effects of PPIs on COVID-19. However, there have been more studies on the effect of PPIs on the occurrence of community acquired pneumonia or hospital acquired pneumonia, but these reports are inconsistent.

several studies suggested that PPIs increased the incidence of community acquired pneumonia, ${ }^{[5-9]}$ and it also showed a statistically significant risk of the incidence of hospital acquired pneumonia. ${ }^{[8-9]}$ Studies reported that the occurrence of pneumonia is related to the duration of proton pump inhibitor use, and its short-term use increased the risk of pneumonia. ${ }^{[5,10-11]}$ The risk of pneumonia was related to the dose of proton pump inhibitors, which were found to have a higher risk of pneumonia at high doses. ${ }^{[5,11-12]}$ On the other side, the studies suggested that PPIs did not increase the incidence of pneumonia. They suggested that the increased incidence of pneumonia caused by PPIs was due to confounders, and proton pump itself was not an independent factor affecting the occurrence of pneumonia. ${ }^{[13-16]}$ According to our study, the PPIs use had no relation with the duration of the SARS-CoV-2 clearance and the hospital stay. We preferred the opinion that the PPIs use did not increase the probability of pneumonia. the PPIs use were used at short and conventional doses in our study cases, so we could not provide evidence to assess whether high doses or long-term use of PPIs increase the risk of pneumonia.

Basic studies have shown that PPIs can effectively inhibit virus-specific serine proteases and thus play an antiviral role. ${ }^{[17]}$ And $\mathrm{H}+/ \mathrm{K}+-A T P a s e$ inhibitors can be tried to treat viral infection and respiratory disease. ${ }^{[18]}$ This was inconsistent with our research on the effects of PPIs use on COVID-19. In our study, 
the PPIs use did not shorten the duration of the SARS-CoV-2 clearance. This might be related to the virus species, and more basic studies and clinical studies needed to confirm the effects of proton pump inhibitors use on various virus.

\section{strengths of study}

The data information included in this study was very complete, the study date was continuously monitored, including demographic characteristics and clinical information. Multiple statistical methods were applied to determine whether PPIs use affected the course of COVID-19, effectively excluding the influence of confounders. Therefore, the results are relatively reliable. The study was conducted on COVID-19, which effectively excluded the confounding effects of pneumonia caused by other pathogens. It also makes up for the lack of pathogen parameters in the baseline data from previous studies, which were the relation between PPIs use and pneumonia occurrence.

\section{limitations of study}

The baseline data of our study lacked the viral load of SARS-CoV-2, but lymphocytes and CD4 cells were included as the baseline reference, they could make up for some of the deficiencies in our study, because it was proved that SARS-CoV-2 would affect the change of lymphocyte and CD4 cell counts ${ }^{[21-23]}$. This study included only common COVID-19, and severe and critical cases were not included in the study; therefore, the study does not fully represent the effect of proton pump inhibitors on the course of severe or critical COVID-19. Since the subjects we included in this study are common COVID-19 cases, and PPIs have been used for a short time and at a conventional dose, so the study cannot represent the long-term or high-dose impact of PPIs on the course of COVID-19.

\section{Conclusion}

The use of proton pump inhibitors does not prolong or shorten the duration of the SARS-CoV-2 clearance or hospital stay for COVID-19. Therefore, the appropriate use of proton pump inhibitors in the treatment or prevention of the related diseases will not affect the course of COVID-19.

\section{Declarations}

\section{Ethical Approval and Consent to participate】}

Informed consents of patients were obtained for diagnosis and treatment, and the study. Protocol was approved by the Shanghai Public Health Clinical Center Clinical Committee. All the data received Institutional Review Board (IRB) approval by the Ethics Committee. The IRB number was YJ-2020-S01501.

\section{Consent for publication】}




\section{Availability of supporting data】}

The data included in the manuscript submitted to the journal is transparent. Individual participant data that underlie the results reported in this article after de-identification (text, tables, figures, and appendices). To make the data available, proposals should be directed to the corresponding author of this publication. To gain access, data requestors will need to sign a data access agreement.

\section{Competing interests $\rrbracket$}

The authors declare no conflict of interest.

\section{Funding $₫$}

This research received no external funding.

\section{Authors' contributions $\rrbracket$}

Conceptualization, Xiao-Yu Zhang, Hai-Bing Wu, Yun Ling and Liang Chen; Formal analysis, Xiao-Yu Zhang; Supervision, Liang Chen; Writing - original draft, Xiao-Yu Zhang; Writing - review \& editing, XiaoYu Zhang, Hai-Bing Wu, Yun Ling and Liang Chen.

\section{Acknowledgements $₫$}

This study was supported by the Shanghai Public Health Clinical Center for data access.

\section{Authors' information》}

Hai-Bing Wu, MD, wuhaibing@shphc.org.cn, Department of neurosurgery, Shanghai Public Health Clinical Center, Fudan University, 2901 Cao Lang Road, Shanghai 201508, China; Yun Ling, PhD, lingyun@shphc.org.cn, Department of infectious Disease, Shanghai Public Health Clinical Center, Fudan University, 2901 Cao Lang Road, Shanghai 201508, China; Zhi-Ping Qian, MD, qianzhiping@shphc.org.cn, Department of Severe Hepatopathy, Shanghai Public Health Clinical Center, Fudan University, 2901 Cao Lang Road, Shanghai 201508, China;Liang Chen, MD, chenliang65@yeah.net, Department of Liver Disease, Shanghai Public Health Clinical Center, Fudan University, 2901 Cao Lang Road, Shanghai 201508, China. 


\section{References}

1. Team NCPERE. Vital surveillances: the epidemiological characteristics of an outbreak of 2019 novel coronavirus diseases (COVID-19) - China. China CDC Weekly. 2020;2(8):113 - 22. http://weekly.chinacdc.cn/en/article/id/e53946e2-c6c4-41e9-9a9b-fea8db1a8f51.

2. https://COVID19.who.int/.

3. Huang C, Wang Y, Li X, Ren L, Zhao J, Hu Y, et al. Clinical features of patients infected with 2019 novel coronavirus in Wuhan, China. Lancet. 2020;395(10223):497-506. doi:10.1016/S01406736(20)30183-5. PubMed PMID: 31986264. Epub 2020/01/28.

4. Guan WJ, Ni ZY, Hu Y, et al. Clinical Characteristics of Coronavirus Disease 2019 in China. N Engl J Med. 2020;382(18):1708-20. doi:10.1056/NEJMoa2002032.

5. Sarkar M, Hennessy S, Yang YX. Proton-pump inhibitor use and the risk for community-acquired pneumonia. Ann Intern Med. 2008;149(6):391-8. doi:10.7326/0003-4819-149-6-200809160-00005.

6. Laheij RJ, Sturkenboom MC, Hassing RJ, Dieleman J, Stricker BH, Jansen JB. Risk of communityacquired pneumonia and use of gastric acid-suppressive drugs. JAMA. 2004;292(16):1955-60. doi:10.1001/jama.292.16.1955.

7. Rodríguez LA, Ruigómez A, Wallander MA, Johansson S. Acid-suppressive drugs and communityacquired pneumonia. Epidemiology. 2009;20(6):800-6. doi:10.1097/EDE.0b013e3181b5f27d.

8. Eom CS, Jeon CY, Lim JW, Cho EG, Park SM, Lee KS. Use of acid-suppressive drugs and risk of pneumonia: a systematic review and meta-analysis. CMAJ. 2011;183(3):310-9.

doi:10.1503/cmaj.092129.

9. Herzig SJ, Howell MD, Ngo LH, Marcantonio ER. Acid-suppressive medication use and the risk for hospital-acquired pneumonia. JAMA. 2009;301(20):2120-8. doi:10.1001/jama.2009.722.

10. Vaezi MF, Yang YX, Howden CW. Complications of Proton Pump Inhibitor Therapy. Gastroenterology. 2017;153(1):35-48. doi:10.1053/j.gastro.2017.04.047.

11. Hermos JA, Young MM, Fonda JR, Gagnon DR, Fiore LD, Lawler EV. Risk of community-acquired pneumonia in veteran patients to whom proton pump inhibitors were dispensed. Clin Infect Dis. 2012;54(1):33-42. doi:10.1093/cid/cir767.

12. Giuliano C, Wilhelm SM, Kale-Pradhan PB. Are proton pump inhibitors associated with the development of community-acquired pneumonia? A meta-analysis. Expert Rev Clin Pharmacol. 2012;5(3):337-44. doi:10.1586/ecp.12.20.

13. Othman F, Crooks CJ, Card TR. Community acquired pneumonia incidence before and after proton pump inhibitor prescription: population based study. BMJ. 2016;355:i5813. doi:10.1136/bmj.i5813. Published 2016 Nov 15.

14. Filion KB, Chateau D, Targownik LE, et al. Proton pump inhibitors and the risk of hospitalisation for community-acquired pneumonia: replicated cohort studies with meta-analysis. Gut. 2014;63(4):5528. doi:10.1136/gutjnl-2013-304738. 
15. Marker S, Barbateskovic M, Perner A, et al. Prophylactic use of acid suppressants in adult acutely ill hospitalised patients: A systematic review with meta-analysis and trial sequential analysis [published online ahead of print, 2020 Feb 15]. Acta Anaesthesiol Scand. 2020. 10.1111/aas.13568. doi:10.1111/aas.13568.

16. Wang $\mathrm{CH}$, $\mathrm{Li} \mathrm{CH}$, Hsieh R, et al. Proton pump inhibitors therapy and the risk of pneumonia: a systematic review and meta-analysis of randomized controlled trials and observational studies. Expert Opin Drug Saf. 2019;18(3):163-72. doi:10.1080/14740338.2019.1577820.

17. Moorman AE, Becker DP, Flynn DL. Method of using $(\mathrm{H}+/ \mathrm{K}+)$ ATPase inhibitors as antiviral agents: US6906078[P]. 2005-06-14. http://www.freepatentsonline.com/6906078.html.

18. Li H, Meng L, Liu F, et al. H+/K+-ATPase inhibitors: a patent review [J]. Expert Opin Ther Pat. 2013;23(1):99-111. doi: 10.1517/13543776.2013.741121. Epub 2012 Dec 4.

19. Sanders JM, Monogue ML, Jodlowski TZ, Cutrell JB. Pharmacologic Treatments for Coronavirus Disease 2019 (COVID-19): A Review [published online ahead of print, 2020 Apr 13. JAMA. 2020. 10.1001/jama.2020.6019. doi:10.1001/jama.2020.6019.

20. Beigel JH, Tomashek KM, Dodd LE, et al. Remdesivir for the Treatment of Covid-19 - Preliminary Report [published online ahead of print, 2020 May 22]. N Engl J Med. 2020. 10.1056/NEJMoa2007764. doi:10.1056/NEJMoa2007764.

21. Liu Y, Yang Y, Zhang C, et al. Clinical and biochemical indexes from 2019-nCoV infected patients linked to viral loads and lung injury. Sci China Life Sci. 2020;63(3):364-74. doi:10.1007/s11427-0201643-8.

22. Wang D, Hu B, Hu C, et al. Clinical Characteristics of 138 Hospitalized Patients With 2019 Novel Coronavirus-Infected Pneumonia in Wuhan, China [published online ahead of print, 2020 Feb 7]. JAMA. 2020;323(11):1061-9. doi:10.1001/jama.2020.1585.

23. Tan L, Wang Q, Zhang D, et al. Lymphopenia predicts disease severity of COVID-19: a descriptive and predictive study. Signal Transduct Target Ther. 2020;5(1):33. doi:10.1038/s41392-020-0148-4. Published 2020 Mar 27.

\section{Figures}




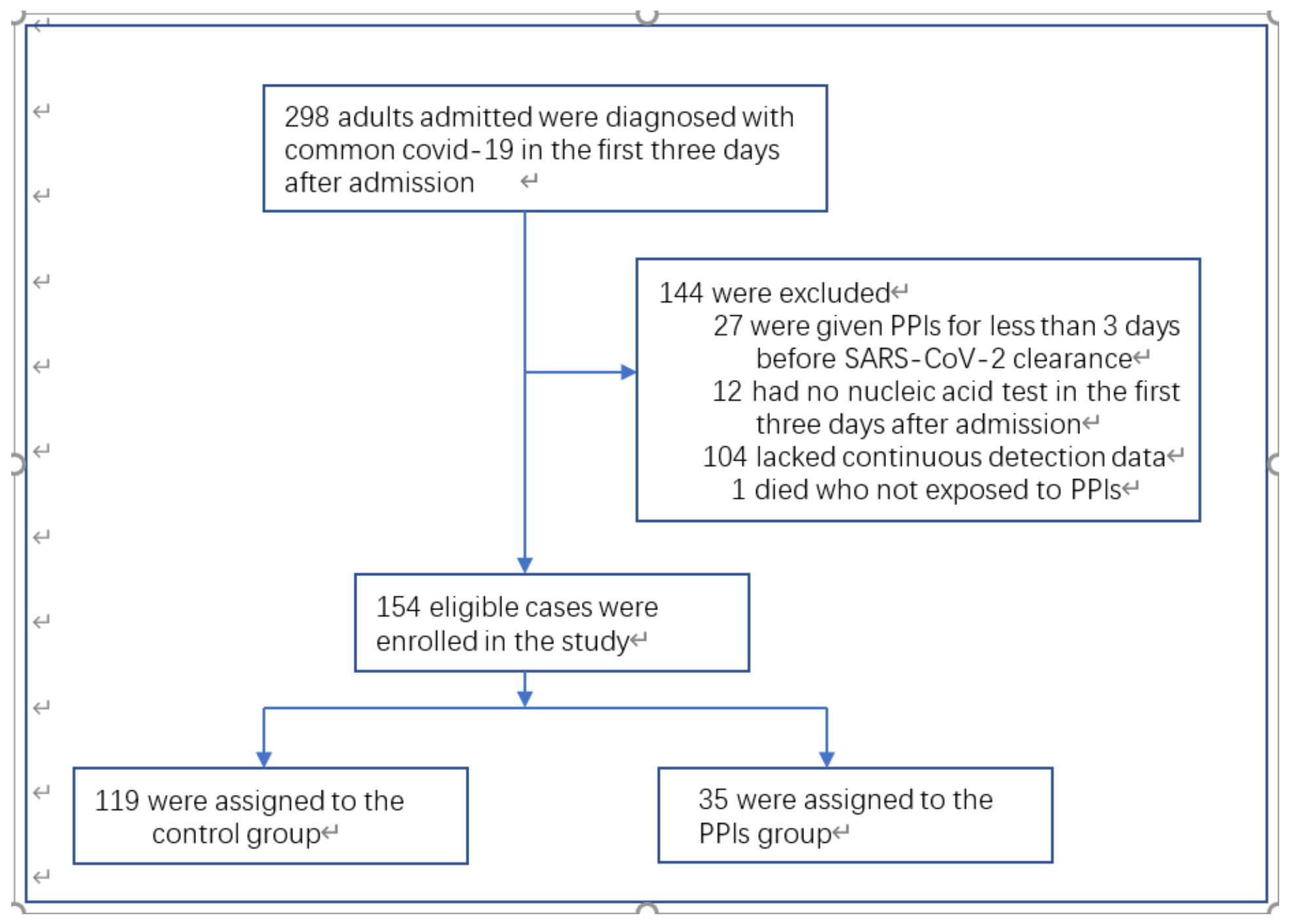

Figure 1

Study Cohort. 
A

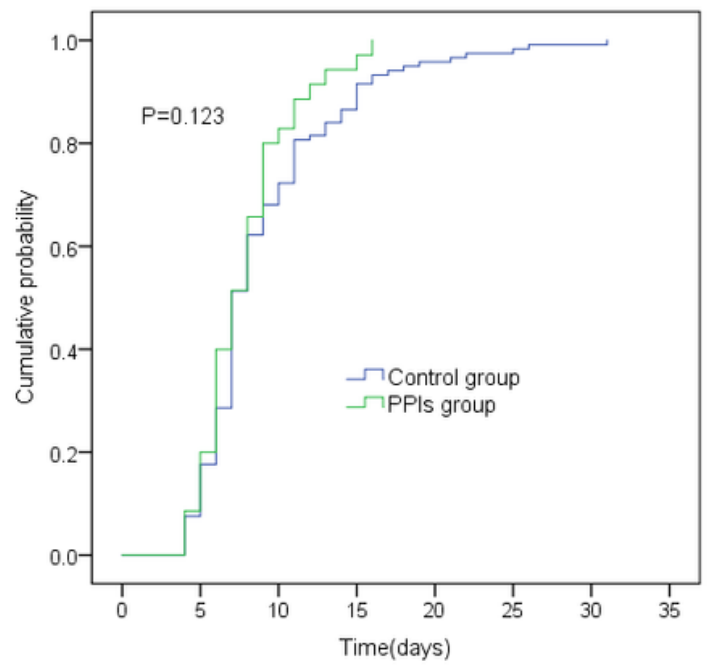

No. at Risk

$\begin{array}{lcccccccc}\text { Control group } & 119 & 98 & 33 & 10 & 5 & 2 & 1 & 0 \\ \text { PPIs group } & 35 & 28 & 6 & 1 & 0 & 0 & 0 & 0\end{array}$
B

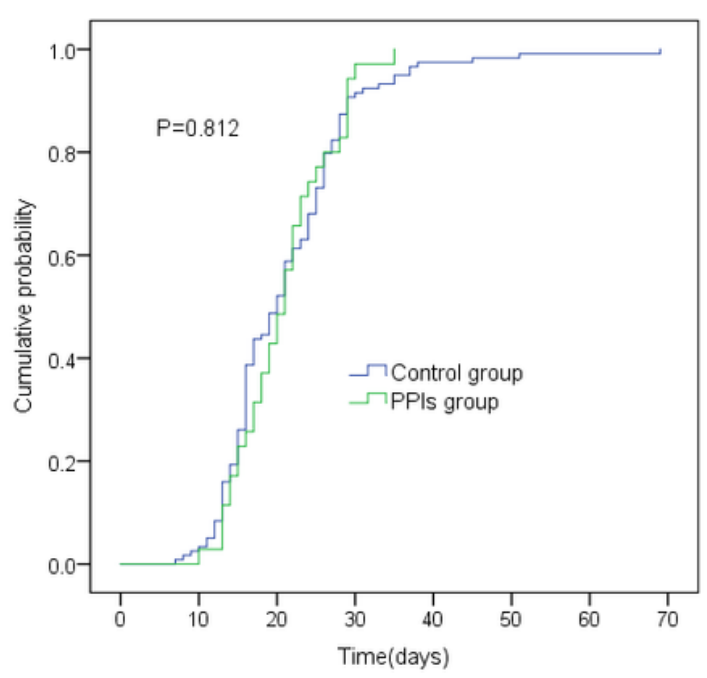

No. at Risk

$\begin{array}{lcccccccc}\text { Control group } & 119 & 115 & 57 & 10 & 3 & 2 & 1 & 0 \\ \text { PPIs group } & 35 & 34 & 18 & 1 & 0 & 0 & 0 & 0\end{array}$

Figure 2

Cumulative probability of SARS-CoV-2 clearance and discharge in COVID-19 patients between PPIs group and control group. Kaplan-Meier curves of (A) SARS-CoV-2 clearance and (B) discharge in the enrolled cases. 